\title{
Perbedaan Karakteristik dan Pelanggaran Lalu Lintas oleh Pengendara Sepeda Motor pada Jalan Banda Aceh-Medan dan Jalan Banda Aceh-Meulaboh
}

\author{
Zafara Quratul Ayuni ${ }^{1}$ Renni Anggraini ${ }^{2}$ Yusria Darma ${ }^{3}$ \\ ${ }^{1}$ Mahasiswa, Jurusan Teknik Sipil, Universitas Syiah Kuala, Banda Aceh 23111, Indonesia \\ ${ }^{2,3}$ Jurusan Teknik Sipil, Universitas Syiah Kuala, Banda Aceh 23111, Indonesia \\ Email: zafaraayuni96@gmail.com
}

\begin{abstract}
Traffic violations are a common problem and may endanger the safety of other motorists. Violation is one of the factors of traffic accidents, most traffic accidents are caused by motorcyclists who driving without discipline. This research aims to determine the relationship between traffic volume, average speed of motorcycles, and violations of motorcyclists on the accident rate and to find out if there is a significant difference of violations between of the two roads which is conducted on kilometer 8,5 of Banda Aceh-Medan Road and kilometer 1,5 of Cut Nyak Dhien Road, Banda Aceh-Meulaboh. These roads are national road which have the same function as primary arterial road, that consists of four lanes-two directions (4/2 D) and separated by the median. The method of collecting data was conducted in direct observation of motorcyclists, with 2 people on each road as a surveyor. The instrument on this research was cameras, survey forms, stopwatch, and measuring instrument for traffic volume, average speed of motorcycles, and violations of motorcyclists observation. Data analysis in this research used descriptive statistical analysis method dan Chi-Square test. The result shows that roads with high accident rates have low traffic volumes, high average speed, and the number of violation by motorcycle is more higher than the roads with low accident rate. The result of the comparasion between two segment of roads by using Chi-square test has the value of chi-square > tabel of Chi-square, then alternative hypothesis is accepted which indicates there is a significant difference of violation by motorcyclists between the two roads
\end{abstract}

Keywords : Traffic accidents, motorcyclist, violation of motorcycle, observation, Chi-Square test.

\begin{abstract}
Abstrak
Pelanggaran lalu lintas merupakan suatu bentuk masalah yang sering terjadi dan dapat membahayakan keselamatan pengguna jalan lainnya. Pelanggaran merupakan salah satu faktor penyebab terjadinya kecelakaan lalu lintas, sebagian besar kecelakaan lalu lintas diakibatkan oleh pengendara sepeda motor yang melakukan pelanggaran dan berkendara dengan tidak disiplin. Penelitian ini bertujuan untuk mengetahui kaitan antara volume lalu lintas, kecepatan rata-rata sepeda motor dan pelanggaran pengendara sepeda motor terhadap besarnya angka kecelakaan pada suatu jalan serta untuk mengetahui apakah terdapat perbedaan pelanggaran pengendara sepeda motor yang signifikan antara kedua jalan yaitu Jalan Banda Aceh-Medan KM 8,5 dan Jalan Cut Nyak Dhien lintas Banda Aceh-Meulaboh KM 1,5. Kedua jalan ini merupakan jalan nasional dengan fungsi jalan yang sama yaitu jalan arteri primer yang terdiri dari empat lajur dua arah dan dipisahkan oleh median (4/2D). Pengumpulan data dilakukan dengan observasi langsung terhadap pengendara sepeda motor, dengan jumlah surveyor sebanyak 2 orang. Penelitian ini menggunakan instrumen berupa alat rekam, formulir survei, stopwatch, dan alat ukur untuk pengumpulan data voume lalu lintas, kecepatan rata-rata sepeda motor, dan pelanggaran pengendara sepeda motor. Pengolahan data dilakukan dengan menggunakan analisis statistik deskriptif dan uji chi-square. Dari hasil penelitian perbandingan 2 segmen jalan, diketahui bahwa jalan dengan angka kecelakaan tinggi memiliki volume lalu lintas yang relatif lebih rendah, kecepatan rata-rata relatif lebih tinggi dan jumlah pelanggaran pengendara sepeda motor yang relatif lebih tinggi dibandingkan jalan dengan angka kecelakaan rendah. Hasil perbandingan pelanggaran dengan menggunakan uji chi-square diperoleh nilai chi-square hitung > chi-square tabel, maka hasil pada pengujian ini adalah penerimaan hipotesis alternatif $\left(\mathrm{H}_{\mathrm{a}}\right)$ yaitu terdapat perbedaan pelanggaran pengendara sepeda motor yang signifikan pada jalan dengan angka kecelakaan tinggi dan rendah.
\end{abstract}

Kata Kunci : kecelakaan lalu lintas, pelanggaran sepeda motor, pengendara sepeda motor, uji Chi-Square.

\section{Pendahuluan}

Pelanggaran peraturan lalu lintas merupakan suatu bentuk masalah yang sering terjadi dan dapat membahayakan keselamatan pengguna jalan lainnya. Pelanggaran itu sendiri merupakan suatu keadaan dimana terjadinya ketidaksesuaian antara peraturan dan pelaksanaan. Pelanggaran merupakan salah satu faktor penyebab terjadinya kecelakaan lalu lintas dan dapat menimbulkan banyak kerugian baik material maupun non material akibatnya.
Berdasarkan data dari Satlantas Polresta Banda Aceh, angka kecelakaan pada Jalan Banda Aceh-Medan tahun 2017 sebanyak 17 kasus laka dan tahun 2018 sebanyak 13 kasus laka, sedangkan angka kecelakaan pada Jalan Cut Nyak Dhien lintas Banda Aceh-Meulaboh tahun 2017 sebanyak 4 kasus laka dan tahun 2018 sebanyak 9 kasus laka. Melihat angka kecelakaan pada jalan Banda Aceh-Medan lebih tinggi dari Jalan Banda Aceh-Meulaboh, akan dilakukan penelitian untuk 
membandingkan angka pelanggaran yang dilakukan oleh pengendara sepeda motor di kedua jalan tersebut.

Berdasarkan latar belakang dan permasalahan diatas, tujuan dari penelitian ini adalah untuk mengetahui kaitan antara volume lalu lintas, kecepatan rata-rata kendaraan, serta pelanggaran lalu lintas terhadap besarnya angka kecelakaan pada suatu jalan, dan untuk mengetahui perbedaan pelanggaran pengendara sepeda motor pada jalan dengan angka kecelakaan tinggi dan jalan dengan angka kecelakaan rendah.

Dalam penelitian ini pengamatan dilakukan pada dua ruas jalan, yaitu Jalan Banda Aceh-Medan KM 8,5 kecamatan ingin jaya sebagai jalan yang memiliki angka kecelakaan tinggi dan Jalan Cut Nyak Dhien, Banda Aceh-Meulaboh KM 1,5 kecamatan jaya baru sebagai jalan yang memiliki angka kecelakaan rendah.

Penelitian ini dilakukan dengan cara observasi langsung volume lalu lintas, kecepatan rata-rata kendaraan sepeda motor, serta pelanggaran pengendara sepeda motor sesuai Undang-Undang Nomor 22 Tahun 2009 yang dapat diamati secara langsung saat pengamatan, yaitu pelanggaran kelengkapan pengendara berupa penggunaan helm, spion, dan lampu utama serta perilaku pengendara berupa melawan arus, kurangnya konsentrasi saat berkendara, dan muatan berlebih. Pengamatan dilakukan selama 3 hari yaitu hari Senin, Rabu dan Sabtu pada pukul 07.00-08.00 WIB, 12.0013.00 WIB, dan 17.00-18.00 WIB.

Pengambilan data dilakukan oleh 2 surveyor dengan menggunakan 2 buah kamera untuk merekam, yang selanjutnya akan dihitung volume lalu lintas serta pelanggaran pengendara sepeda motor pada kedua jalan yang ditinjau. Pengumpulan data kecepatan rata-rata sepeda motor dilakukan secara manual dengan menggunakan stopwatch. Panjang pias pengamatan adalah sepanjang 70 meter dengan sampel yang diambil sebanyak 6 sepeda motor per 15 menit pengamatan.

Hasil dari penelitian ini dapat disimpulkan bahwa Jalan dengan angka kecelakaan tinggi memiliki volume lalu lintas yang relatif rendah, kecepatan rata-rata relatif tinggi, dan jumlah pelanggaran pengendara sepeda motor yang relatif lebih tinggi, sedangkan jalan dengan angka kecelakaan rendah memiliki volume lalu lintas yang relatif lebih tinggi, kecepatan rata-rata relatif rendah dan jumlah pelanggaran pengendara sepeda motor yang relatif lebih rendah, serta hasil hipotesis dari pengujian chi-square berupa penerimaan hipotesis alternatif $\left(\mathrm{H}_{\mathrm{a}}\right)$ yaitu terdapat perbedaan pelanggaran pengendara sepeda motor yang signifikan pada jalan dengan angka kecelakaan tinggi dan rendah.

Dari grafik dan tabel hasil pelanggaran diketahui bahwa angka pelanggaran yang dilakukan pengendara sepeda motor pada Jalan Banda Aceh-Medan relatif lebih tinggi dibandingkan Jalan Banda Aceh-Meulaboh. Pelanggaran pada kedua jalan ini didominasi oleh pengendara laki-laki yaitu 78,9\% di Jalan Banda AcehMedan dan 73,4\% di Jalan Banda Aceh-Meulaboh.

\section{Tinjauan Kepustakaan}

\subsection{Lalu Lintas}

Menurut Undang-Undang Nomor 22 tahun 2009 tentang lalu lintas dan angkutan jalan [1], lalu lintas adalah pergerak kendaraan dan orang di ruang lalu lintas jalan. Ruang lalu lintas jalan adalah prasarana yang diperuntukkan bagi gerak pindah kendaraan, orang, dan/atau barang yang berupa jalan dan fasilitas pendukung.

\subsection{Pelanggaran Lalu Lintas}

Menurut Ramdlon Naning (1983), pelanggaran lalu lintas adalah perbuatan atau tindakan yang bertentangan dengan ketentuan-ketentuan peraturan perundang-undangan lalu lintas (Sainuddin,2015) [2].

\subsection{Kecelakaan Lalu Lintas}

Menurut Undang-Undang Nomor 22 tahun 2009 tentang lalu lintas dan angkutan jalan, kecelakaan lalu lintas adalah suatu peristiwa di jalan yang tidak diduga dan tidak disengaja melibatkan kendaraan dengan atau tanpa pengguna jalan lain yang melibatkan korban manusia dan/atau kerugian harta benda.

\subsection{Volume Lalu Lintas}

Sukirman (1999) [3] menyatakan, volume lalu lintas adalah jumlah kendaraan yang melintasi satu titik atau tampang melintang jalan dalam satu satuan waktu tertentu, yang diukur dan dinyatakan dalam satuan kendaraan per satuan waktu.

\subsection{Kecepatan Lalu Lintas}

Menurut Sukirman (1999), kecepatan adalah besaran yang menunjukkan jarak tempuh kendaraan pada suatu ruas jalan dibagi dengan waktu tempuh, biasanya dinyatakan dalam kilometer per jam ( $\mathrm{km} / \mathrm{jam})$.

\subsection{Uji Chi-Square}

Menurut Santoso (2001) [4], Chi-Square termasuk salah satu alat uji dalam statistik yang sering digunakan dalam praktek. Chi-Square adalah salah satu jenis uji komparatif non parametris yang dilakukan pada dua variabel, dimana skala data kedua variabel adalah nominal. Cara menghitung chi-square dengan bentuk tabel kontingensi lebih dri 2 x 2 akan menggunakan rumus pearson chi-square. Perumusannya adalah sebagai berikut:

$X^{2}=\sum \frac{(F o-F h)^{2}}{F h}$

Keterangan:

$\mathrm{X}^{2}=$ Nilai chi-square.

$\mathrm{F}_{\mathrm{o}}=$ frekuensi yang diperoleh dari sampel yang diamati atau hasil observasi.

$\mathrm{F}_{\mathrm{h}}=$ frekuensi yang diharapkan dalam sampel sebagai pencerminan dari frekuensi yang diharapkan dalam populasi.

\section{Metodologi Penelitian}

\subsection{Obyek Penelitian}


ISSN 2685-0605

Penelitian ini meninjau pelanggaran yang dilakukan pengendara sepeda motor pada kedua jalan yang ditinjau, yaitu jalan Banda Aceh-Medan KM 8,5 Kecamatan Ingin Jaya, dan jalan Cut Nyak Dhien lintas Banda Aceh-Meulaboh KM 1,5 Kecamatan Jaya Baru.

\subsection{Teknik Pengumpulan Data}

Penelitian ini menggunakan data primer dan data sekunder. Data primer diperoleh dari pengamatan langsung di kedua ruas jalan yang ditinjau. Data primer yang dibutuhkan adalah data volume lalu lintas, kecepatan rata-rata kendaraan, dan pelanggaran lalu lintas. Data sekunder terdiri atas peta provinsi Aceh dan Kota Banda Aceh serta data kecelakaaan lalu lintas yang didapat dari Sat Lantas Polresta Banda Aceh.

\subsection{Teknik Analisis Data}

Teknik analisis data pada penelitian ini terdiri dari analisis statistik deskriptif dan uji chi-square. Analisis statistik deskriptif menyajikan hasil observasi volume lalu lintas, kecepatan sepeda motor, serta pelanggaran pengendara sepeda motor dalam bentuk distribusi frekuensi dan persentase. Uji chi-square menyajikan hasil berupa penarikan kesimpulan hipotesis apakah terdapat perbedaan pelanggaran pengendara sepeda motor pada jalan dengan angka kecelakaan tinggi dan jalan dengan angka kecelakaan rendah.

\section{Hasil dan Pembahasan}

\subsection{Hasil Penelitian}

\subsubsection{Hasil Survey Volume Lalu Lintas}

Hasil Rekapitulasi survey volume lalu lintas yang diperoleh menunjukan bahwa volume lalu lintas pada Jalan Banda Aceh-Meulaboh lebih besar dibandingkan pada Jalan Banda Aceh-Medan.

Tabel 1 Rekapitulasi volume lalu lintas pada Jalan Banda Aceh-Medan.

\begin{tabular}{|c|c|c|c|c|c|c|}
\hline \multirow{2}{*}{ Hari } & \multirow{2}{*}{ Jam } & \multicolumn{3}{|c|}{ Volume } & \multirow{2}{*}{$\begin{array}{c}\text { Jumlah } \\
\text { (kend/ } \\
\text { jam) }\end{array}$} & \multirow{2}{*}{$\begin{array}{c}\text { Volume } \\
\text { (smp/jam) }\end{array}$} \\
\hline & & MC & LV & HV & & \\
\hline 1 & 2 & 3 & 4 & 5 & $\begin{array}{c}(6)= \\
(3)+(4) \\
+(5) \\
\end{array}$ & $\begin{array}{c}(7)= \\
(3)(a)+(4)(b) \\
+(5)(c)\end{array}$ \\
\hline \multirow{3}{*}{$\begin{array}{l}\text { Senin } \\
\text { (29 Juli } \\
\text { 2019) }\end{array}$} & 07.00-08.00 & 2851 & 904 & 78 & 3833 & 1710 \\
\hline & $12.00-13.00$ & 2392 & 891 & 70 & 3353 & 1573 \\
\hline & $17.00-18.00$ & 3750 & 1055 & 118 & 4923 & 2134 \\
\hline \multirow{3}{*}{$\begin{array}{l}\text { Rabu } \\
\text { (31 Juli } \\
\text { 2019) }\end{array}$} & $07.00-08.00$ & 2760 & 924 & 84 & 3768 & 1715 \\
\hline & $12.00-13.00$ & 2351 & 856 & 118 & 3325 & 1585 \\
\hline & $17.00-18.00$ & 3492 & 1032 & 92 & 4616 & 2015 \\
\hline \multirow{3}{*}{$\begin{array}{l}\text { Sabtu } \\
\text { (27 Juli } \\
\text { 2019) }\end{array}$} & $07.00-08.00$ & 2543 & 836 & 81 & 3460 & 1569 \\
\hline & $12.00-13.00$ & 2325 & 880 & 104 & 3309 & 1586 \\
\hline & $17.00-18.00$ & 3350 & 1219 & 105 & 4674 & 2183 \\
\hline \multicolumn{2}{|c|}{ Total } & 25814 & 8597 & 850 & 35261 & 16071 \\
\hline \multicolumn{2}{|c|}{ Persen } & 73,21 & 24,38 & 2,41 & 100 & \\
\hline
\end{tabular}

Tabel 2 Rekapitulasi volume lalu lintas pada Jalan Banda Aceh-Meulaboh.

\begin{tabular}{|c|c|c|c|c|c|c|}
\hline \multirow[b]{2}{*}{ Hari } & \multirow[b]{2}{*}{ Jam } & \multicolumn{3}{|c|}{ Volume } & \multirow{2}{*}{$\begin{array}{c}\text { Jumlah } \\
\text { (kend/ } \\
\text { jam) }\end{array}$} & \multirow{2}{*}{$\begin{array}{l}\text { Volume } \\
\text { (smp/jam) }\end{array}$} \\
\hline & & MC & LV & $\mathrm{HV}$ & & \\
\hline 1 & 2 & 3 & 4 & 5 & $\begin{array}{c}(6)= \\
(3)+(4) \\
+(5)\end{array}$ & $\begin{array}{c}(7)= \\
(3)(a)+(4)(b) \\
+(5)(c)\end{array}$ \\
\hline \multirow{3}{*}{$\begin{array}{l}\text { Senin } \\
\text { (29 Juli } \\
\text { 2019) }\end{array}$} & $07.00-08.00$ & 3243 & 902 & 28 & 4173 & 1746 \\
\hline & $12.00-13.00$ & 2713 & 872 & 22 & 3607 & 1577 \\
\hline & $17.00-18.00$ & 3708 & 1231 & 25 & 4964 & 2188 \\
\hline \multirow{3}{*}{$\begin{array}{l}\text { Rabu } \\
\text { (31 Juli } \\
\text { 2019) }\end{array}$} & $07.00-08.00$ & 3289 & 885 & 24 & 4198 & 1736 \\
\hline & $12.00-13.00$ & 2807 & 864 & 24 & 3695 & 1595 \\
\hline & $17.00-18.00$ & 3875 & 1217 & 41 & 5133 & 2235 \\
\hline \multirow{3}{*}{$\begin{array}{l}\text { Sabtu } \\
\text { (27 Juli } \\
2019)\end{array}$} & $07.00-08.00$ & 2643 & 997 & 18 & 3658 & 1679 \\
\hline & $12.00-13.00$ & 2571 & 920 & 30 & 3521 & 1599 \\
\hline & $17.00-18.00$ & 3436 & 1388 & 36 & 4860 & 2290 \\
\hline \multicolumn{2}{|c|}{ Total } & 28285 & 9276 & 248 & 37809 & 16645 \\
\hline \multicolumn{2}{|c|}{ Persen } & 74,81 & 24,53 & 0,66 & 100 & \\
\hline
\end{tabular}

Dari tabel rekapitulasi volume lalu lintas diatas terlihat bahwa pada Jalan Banda Aceh-Medan jumlah kendaraan sepeda motor (MC) sebanyak 73,21\%, kendaraan ringan (LV) sebanyak $24,38 \%$ dan kendaraan berat (HV) sebanyak 2,41\%. Sedangkan pada Jalan Banda Aceh-Melaboh memiliki jumlah kendaraan yan lebih banyak, yaitu sepeda motor (MC) sebanyak $74,81 \%$, kendaraan ringan (LV) sebanyak $24,53 \%$ dan kendaraan berat (HV) sebanyak $0,66 \%$.

\subsubsection{Hasil Survey kecepatan Lalu Lintas}

Hasil Rekapitulasi survey kecepatan lalu lintas yang diperoleh pada kedua jalan yang ditinjau menunjuan bahwa kecepatan rata-rata sepeda motor pada Jalan Banda Aceh-Medan lebih tinggi dibandingkan pada Jalan Banda Aceh-Medan.

Tabel 3 Rekapitulasi kecepatan kendaraan Jalan Banda Aceh-Medan.

\begin{tabular}{|c|c|c|c|c|}
\hline Ruas Jalan & $\begin{array}{l}\text { Hari / } \\
\text { Tanggal }\end{array}$ & Waktu & $\begin{array}{c}\text { Kecepatan } \\
\text { Rata-Rata } \\
(\mathrm{km} / \mathrm{jam})\end{array}$ & $\begin{array}{c}\text { Kecepatan } \\
\text { Rata-Rata } \\
(\mathrm{km} / \mathrm{jam})\end{array}$ \\
\hline \multirow{3}{*}{$\begin{array}{l}\text { B.Aceh- } \\
\text { Medan }\end{array}$} & \multirow{3}{*}{$\begin{array}{l}\text { Senin } \\
\text { (29 Juli } \\
\text { 2019) }\end{array}$} & $07.00-08.00$ & 49,31 & \multirow{3}{*}{48,73} \\
\hline & & $12.00-13.00$ & 48,96 & \\
\hline & & $17.00-18.00$ & 47,92 & \\
\hline \multirow{3}{*}{$\begin{array}{l}\text { B.Aceh- } \\
\text { Medan }\end{array}$} & \multirow{3}{*}{$\begin{array}{l}\text { Rabu } \\
\text { (31 Juli } \\
\text { 2019) }\end{array}$} & $07.00-08.00$ & 49,02 & \multirow{3}{*}{49,34} \\
\hline & & $12.00-13.00$ & 49,22 & \\
\hline & & $17.00-18.00$ & 49,77 & \\
\hline \multirow[t]{2}{*}{$\begin{array}{l}\text { B.Aceh- } \\
\text { Medan }\end{array}$} & \multirow[t]{2}{*}{$\begin{array}{l}\text { Sabtu (27 } \\
\text { Juli 2019) }\end{array}$} & $07.00-08.00$ & 49,32 & \multirow[t]{2}{*}{48,53} \\
\hline & & $12.00-13.00$ & 48,05 & \\
\hline
\end{tabular}




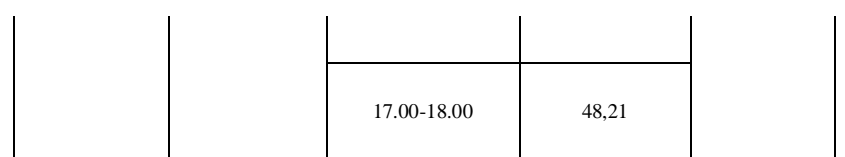

Tabel 4 Rekapitulasi kecepatan kendaraan Jalan Banda Aceh-Meulaboh.

\begin{tabular}{|c|c|c|c|c|}
\hline Ruas Jalan & $\begin{array}{l}\text { Hari / } \\
\text { Tanggal }\end{array}$ & Waktu & $\begin{array}{c}\text { Kecepatan } \\
\text { Rata-Rata } \\
\text { (km/jam) }\end{array}$ & $\begin{array}{c}\text { Kecepatan Rata-Rata } \\
(\mathrm{km} / \mathrm{jam})\end{array}$ \\
\hline \multirow{3}{*}{$\begin{array}{l}\text { B.Aceh- } \\
\text { Meulaboh }\end{array}$} & \multirow{3}{*}{$\begin{array}{l}\text { Senin (29 } \\
\text { Juli 2019) }\end{array}$} & $07.00-08.00$ & 42,83 & \multirow{3}{*}{43,23} \\
\hline & & $12.00-13.00$ & 43,16 & \\
\hline & & $17.00-18.00$ & 43,71 & \\
\hline \multirow{3}{*}{$\begin{array}{l}\text { B.Aceh- } \\
\text { Meulaboh }\end{array}$} & \multirow{3}{*}{$\begin{array}{c}\text { Rabu (31 } \\
\text { Juli 2019) }\end{array}$} & $07.00-08.00$ & 44,12 & \multirow{3}{*}{43,72} \\
\hline & & $12.00-13.00$ & 43,73 & \\
\hline & & $17.00-18.00$ & 43,32 & \\
\hline \multirow{3}{*}{$\begin{array}{l}\text { B.Aceh- } \\
\text { Meulaboh }\end{array}$} & \multirow{3}{*}{$\begin{array}{c}\text { Sbtu (27 Juli } \\
\text { 2019) }\end{array}$} & $07.00-08.00$ & 44,16 & \multirow{3}{*}{44,36} \\
\hline & & $12.00-13.00$ & 44,57 & \\
\hline & & $17.00-18.00$ & 44,36 & \\
\hline
\end{tabular}

\subsubsection{Hasil Survey Pelanggaran Lalu Lintas}

a. Jenis Kelamin

Gambar 1 Pelanggaran pengendara berdasarkan jenis kelamin di Jalan Banda Aceh-Medan.

Pelanggaran Berdasarkan Jenis Kelamin

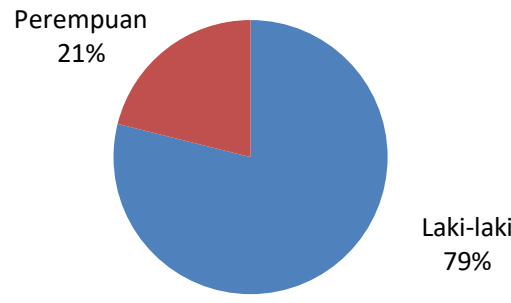

Gambar 2 Pelanggaran pengendara berdasarkan jenis kelamin di Jalan Banda Aceh-Meulaboh.

\section{Pelanggaran Berdasarkan Jenis Kelamin}

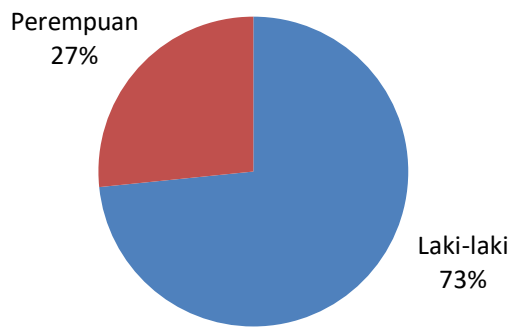

Dari hasil penelitian pelanggaran pengendara sepeda motor berdasarkan jenis kelamin pada kedua jalan yang ditinjau, pengendara laki-laki melakukan pelanggaran lebih banyak dibandingkan pengendara perempuan. Pada jalan Banda Aceh-Medan, jumlah pelanggaran yang dilakukan oleh pengendara laki-laki yaitu sebanyak $78,9 \%$ dan perempuan hanya $21,1 \%$. Sedangkan pada Jalan Banda Aceh-Meulaboh jumlah pelanggaran di dilakukan oleh pengendara laki-laki yaitu sebanyak $73,4 \%$, sedangkan perempuan hanya $26,6 \%$.

\section{b. Penggunaan Helm}

Dari hasil penelitian pelanggaran pengendara sepeda motor berdasarkan penggunaan helm, Jalan Banda Aceh-Medan sebagai jalan dengan angka kecelakaan tinggi memiliki jumlah pelanggaran lebih banyak dari pada Jalan Banda Aceh-Meulaboh sebagai jalan dengan angka kecelakaan rendah. Jumlah pelanggaran di Jalan Banda Aceh-Medan sebanyak $64,41 \%$ dan Jalan Banda Aceh-Meulaboh sebanyak $35,59 \%$.

\section{Gambar 3 Pelanggaran tidak menggunakan helm.}

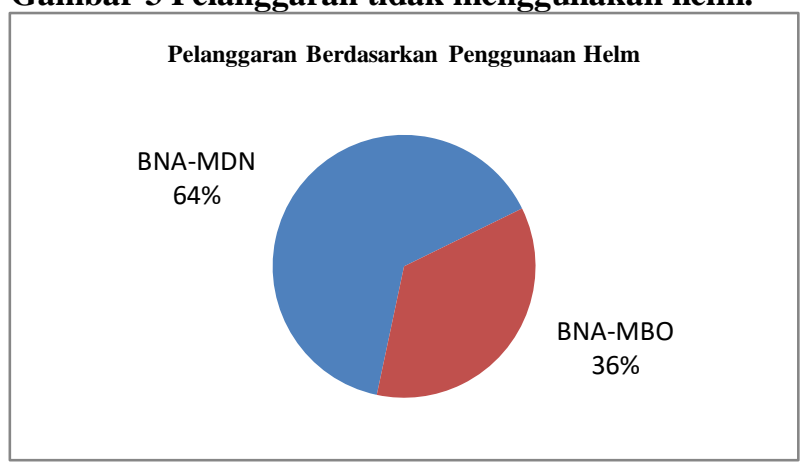

\section{c. Penggunaan Spion}

Dari hasil penelitian pelanggaran pengendara sepeda motor berdasarkan penggunaan spion, Jalan Banda Aceh-Medan memiliki jumlah pelanggaran lebih banyak dari pada Jalan Banda Aceh-Meulaboh. Jumlah pelanggaran di Jalan Banda Aceh-Medan sebanyak $59,87 \%$ dan Jalan Banda Aceh-Meulaboh sebanyak $40,13 \%$. 


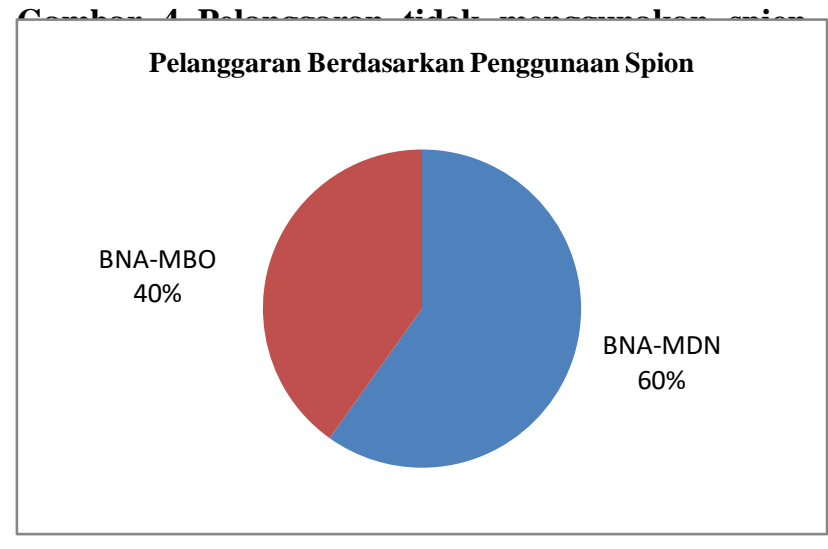

\section{d. Penggunaan Lampu Utama}

Dari hasil penelitian pelanggaran pengendara sepeda motor berdasarkan penggunaan lampu utama di siang hari, Jalan Banda Aceh-Medan memiliki jumlah pelanggaran lebih banyak dari pada Jalan Banda AcehMeulaboh. Jumlah pelanggaran di Jalan Banda AcehMedan sebanyak 58,77\% dan Jalan Banda AcehMeulaboh sebanyak 41,23\%.

Gambar 5 Pelanggaran tidak menggunakan lampu utama.

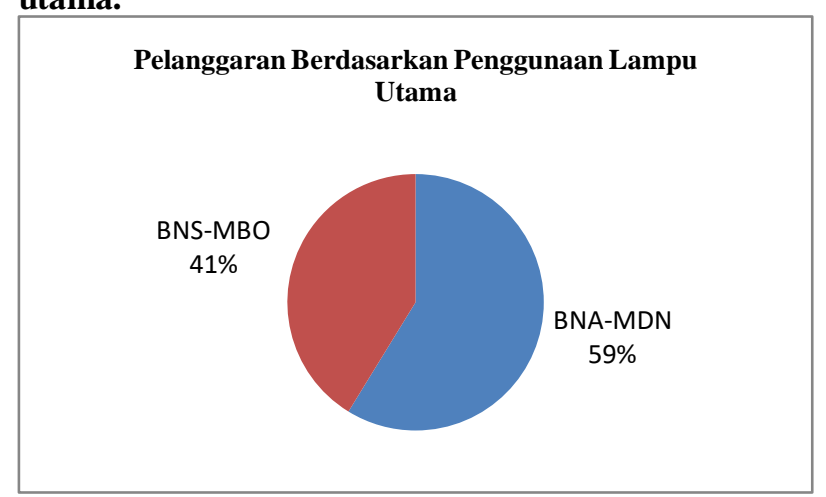

\section{e. Melawan Arus}

Dari hasil penelitian pelanggaran pengendara sepeda motor berdasarkan melawan arus, Jalan Banda Aceh-Medan memiliki jumlah pelanggaran lebih banyak dari pada Jalan Banda Aceh-Meulaboh. Jumlah pelanggaran di Jalan Banda Aceh-Medan sebanyak 62,34\% dan Jalan Banda Aceh-Meulaboh sebanyak $37,66 \%$.

\section{Gambar 6 Pelanggaran melawan arus.}

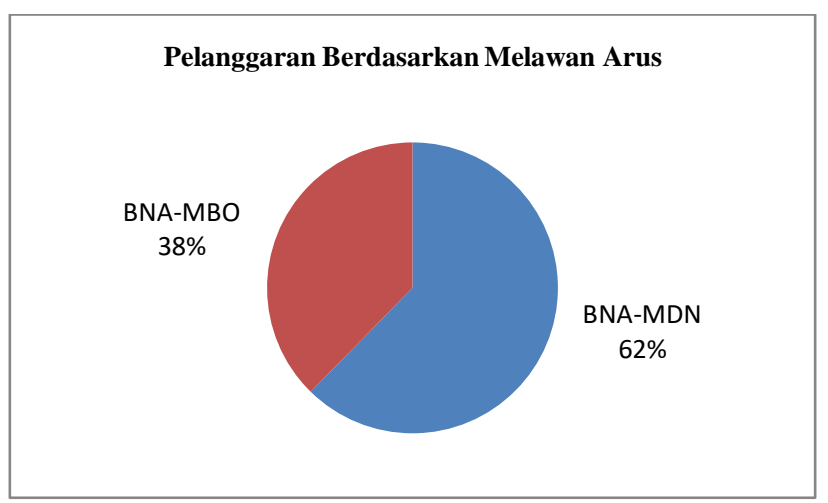

\section{f. Kurangnya konsentrasi}

Dari hasil penelitian pelanggaran pengendara sepeda motor berdasarkan konsentrasi pengendara, Jalan Banda Aceh-Medan sebagai jalan dengan angka kecelakaan tinggi memiliki jumlah pelanggaran lebih banyak dari Jalan Banda Aceh-Meulaboh sebagai jalan dengan angka kecelakaan yang rendah. Persentase pelanggaran di Jalan Banda Aceh-Medan sebanyak $54,55 \%$ dan Jalan Banda Aceh-Meulaboh sebanyak $45,45 \%$.

Gambar 7 Pelanggaran kurangnya konsentrasi.

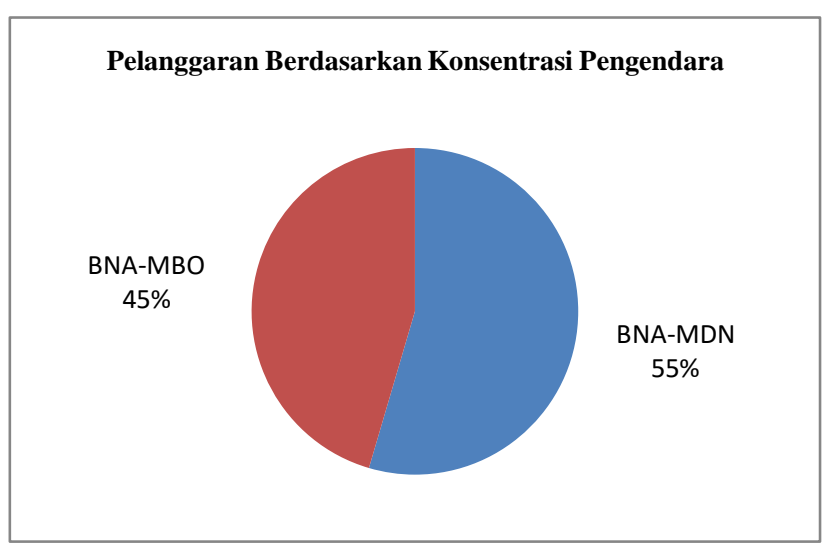

\section{g. Muatan Berlebih}

Dari hasil penelitian pelanggaran pengendara sepeda motor berdasarkan kapasitas penumpang, Jalan Banda Aceh-Medan sebagai jalan dengan angka kecelakaan tinggi memiliki jumlah pelanggaran lebih banyak dari pada Jalan Banda Aceh-Meulaboh sebagai jalan dengan angka kecelakaan rendah. Jumlah pelanggaran di Jalan Banda Aceh-Medan sebanyak 59,21\% dan Jalan Banda Aceh-Meulaboh sebanyak $40,79 \%$.

\section{Gambar 8 Pelanggaran muatan berlebih.}




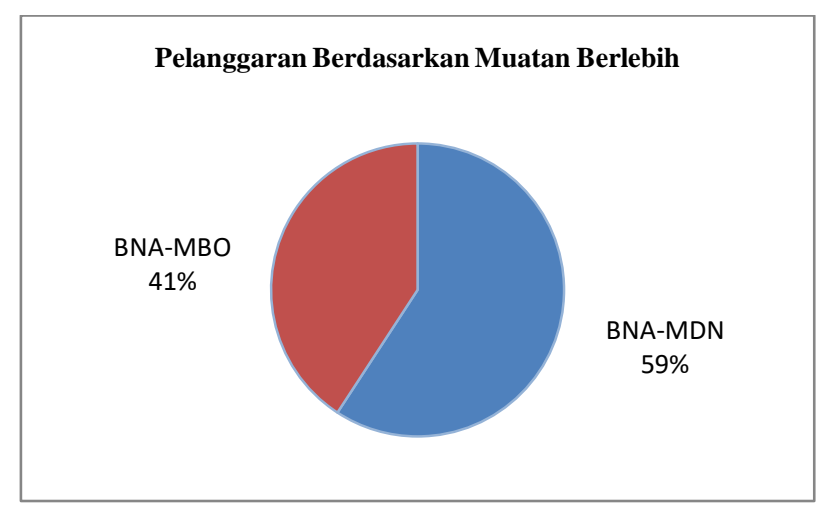

\subsubsection{Hasil Uji Chi-Square Perbandingan Pelanggaran}

Pengolahan data dilakukan dengan menggunakan rumus pearson chi-square untuk didapatkan nilai chisquare hitung. Setelah melakukan pengamatan langsung, data pelanggaran pengendara sepeda motor pada kedua jalan yang telah diperoleh dikelompokkan ke dalam tabel kontingensi yang terdiri dari variabel nama jalan yaitu Jalan Banda Aceh-Medan dan Jalan Banda AcehMeulaboh dan variabel pelanggaran yang terbagi menjadi 2 kategori berupa kelengkapan pengendara yaitu tidak menggunakan helm, spion, dan lampu utama siang hari serta perilaku pengendara yaitu melawan arus, kurangnya konsentrasi, dan muatan berlebih maka tabel kontingensi yang dipakai pada pengujian ini adalah tabel kontingensi $3 \times 2$.

Untuk mecari nilai chi-square hitung digunakan rumus pearson chi-square seperti pada persamaan (2.1), Langkah pertama dalam perhitungan ini adalah mengetahui nilai $F_{0}$ dan $F_{h}$ agar dapat menyelesaikan persamaan pearson chi-square. Nilai $\mathrm{F}_{0}$ adalah frekuensi yang diperoleh dari sampel yaitu pengendara sepeda motor yang melakukan pelanggaran pada kedua jalan, nilai $F_{h}$ adalah frekuensi yang diharapkan dalam sampel, $F_{h}=\{($ jumlah baris/jumlah semua $) \times$ jumlah kolom $\}$ pada tabel kontingensi yang telah dibuat. Berikut merupakan tabel rekapitulasi perhitungan chi-square hitung:

Tabel 5 Rekapitulasi nilai chi-square hitung dan nilai chi-square tabel.

\begin{tabular}{|c|c|c|c|c|}
\hline \multirow[b]{2}{*}{$\begin{array}{c}\text { Hari/ } \\
\text { Tanggal }\end{array}$} & \multirow[b]{2}{*}{ Waktu } & \multicolumn{2}{|c|}{ Nilai Chi-Square Hitung } & \multirow{2}{*}{$\begin{array}{l}\text { Nilai } \\
\text { Chi- } \\
\text { Square } \\
\text { Tabel }\end{array}$} \\
\hline & & $\begin{array}{c}\text { Kelengkapan } \\
\text { Atribut } \\
\text { Pengendara }\end{array}$ & $\begin{array}{c}\text { Perilaku } \\
\text { Pengendara }\end{array}$ & \\
\hline \multirow{3}{*}{$\begin{array}{l}\text { Senin } \\
\text { (29 Juli } \\
2019)\end{array}$} & $07.00-08.00$ & 23,077 & 6,128 & \multirow{6}{*}{5,991} \\
\hline & $12.00-13.00$ & 33,927 & 10,378 & \\
\hline & $17.00-18.00$ & 17,465 & 26,819 & \\
\hline \multirow{3}{*}{$\begin{array}{c}\text { Rabu } \\
\text { (31 Juli } \\
\text { 2019) }\end{array}$} & $07.00-08.00$ & 59,661 & 6,393 & \\
\hline & $12.00-13.00$ & 15,571 & 6,218 & \\
\hline & $17.00-18.00$ & 82,784 & 13,768 & \\
\hline
\end{tabular}

Journal of The Civil Engineering Student

Vol. 3. No. 1, April 2021, Halaman 85-91

\begin{tabular}{|c|c|c|c|}
\hline \multirow{2}{*}{$\begin{array}{c}\text { Sabtu } \\
\text { (27 Juli } \\
\text { 2019) }\end{array}$} & $07.00-08.00$ & 18,344 & 6,572 \\
\cline { 2 - 4 } & $12.00-13.00$ & 42,857 & 27,343 \\
\cline { 2 - 4 } & $17.00-18.00$ & 47,341 & 6,256 \\
\hline
\end{tabular}

Semua nilai chi-square hitung yang diperoleh dari pengujian menggunakan persamaan pearson chi-square akan dibandingkan dengan nilai chi-square tabel untuk mendapatkan kesimpulan berupa penerimaan atau penolakan hipotesis nol $\left(\mathrm{H}_{0}\right)$. Nilai chi-square tabel diperoleh dengan melihat nilai taraf nyata atau taraf signifikansi yang telah ditentukan sebelumnya yaitu $95 \%$ dengan batas kritis 0,05 dan derajat kebebasan atau degree of freedom yang diperoleh dengan persamaan (Df) $=$ (jumlah baris-1) (jumlah kolom-1) yang mana pada pengujian ini variabel baris adalah nama jalan yaitu Jalan Banda Aceh-Medan dan Jalan Banda AcehMeulaboh, dan variabel kolom adalah pelanggaran yang terbagi menjadi 2 kategori, berupa kategori kelengkapan pengendara sepeda motor yaitu tidak menggunakan helm, spion, dan lampu utama siang hari serta kategori perilaku pengendara sepeda motor yaitu melawan arus, kurangnya konsentrasi, dan muatan berlebih. Maka nilai derajat kebebasan adalah $\mathrm{Df}=(2-1)(3-1)=2$.

Setelah membandingkan nilai chi-square hitung dan chi-square tabel maka akan dapat ditarik kesimpulan atau hasil berupa penerimaan hipotesis dan penolakan hipotesis. Hipotesis yang telah ditentukan sebelumnya yaitu hipotesis awal $\left(\mathrm{H}_{0}\right)$ yang berarti tidak ada perbedaan pelanggaran pengendara sepeda motor pada kedua jalan yang ditinjau dan hipotesis alternatif $\left(\mathrm{H}_{\mathrm{a}}\right)$ yang berarti ada perbedaan pelanggaran pengendara sepeda motor pada kedua jalan yang ditinjau.

Penarikan hipotesis ini didapat dengan membandingkan nilai chi-square hitung dan chi-square tabel. Jika nilai chi-square hitung < nilai chi-square tabel maka $\mathrm{H}_{0}$ diterima dan $\mathrm{H}_{\mathrm{a}}$ ditolak, sebaliknya jika nilai chi-square hitung > nilai chi-square tabel maka $\mathrm{H}_{\mathrm{a}}$ diterima dan $\mathrm{H}_{0}$ ditolak.

Semua nilai chi-square hitung yang diperoleh pada pengujian lebih besar dari nilai chi-square tabel maka kesimpulan dari penelitian ini adalah penolakan hipotesis nol $\left(\mathrm{H}_{0}\right)$ atau penerimaan hipotesis alternatif $\left(\mathrm{H}_{\mathrm{a}}\right)$ yaitu terdapat perbedaan pelanggaran berupa kelengkapan dan perilaku pengendara sepeda motor pada Jalan Banda Aceh-Medan sebagai jalan dengan angka kecelakaan tinggi dan Jalan Banda Aceh-Meulaboh sebagai jalan dengan angka kecelakaan rendah.

\subsection{Pembahasan}

Berdasarkan hasil pengumpulan dan analisis data, pada bagian ini akan dikemukakan pembahasan dari hasil survey yang telah dilakukan selama 3 hari dalam 1 minggu yaitu hari Senin, Rabu, dan Sabtu pada dua ruas jalan yaitu Jalan Banda Aceh-Medan KM 8,5 yang merupakan jalan dengan angka kecelakaan tinggi dan Jalan Cut Nyak Dhien, Banda Aceh-Meulaboh KM 1,5 yang merupakan jalan dengan angka kecelakaan rendah, terlihat bahwa Jalan Banda Aceh-Medan menghasilkan 
volume lalu lintas yang lebih rendah yaitu pada hari Senin 21341 smp/hari, hari Rabu 20154 smp/hari, dan hari Sabtu 21825 smp/hari. Jalan Banda Aceh-Meulaboh memiliki volume lalu lintas yang lebih tinggi yaitu pada hari Senin 21880 smp/hari, hari Rabu 22350 smp/hari, dan hari Sabtu 22902 smp/hari.

Hasil Persentase jumlah kendaraan pada Jalan Banda Aceh-Medan yaitu sepeda motor (MC) sebesar $73,21 \%$, kendaraan ringan (LV) sebesar 24,38\%, dan kendaraan berat (HV) sebesar 2,41\% sedangkan pada Jalan Banda Aceh-Meulaboh persentase jumlah kendaraan sepeda motor (MC) sebesar 74,81\%, kendaraan ringan (LV) sebesar 24,53\%, dan kendaraan berat (HV) sebesar 0,66\%. Dari hasil penelitian ini dapat disimpulkan bahwa Jalan Banda Aceh-Meulaboh yaitu jalan dengan angka kecelakaan rendah memiliki volume lalu lintas yang relatif lebih tinggi dibandingkan pada Jalan Banda Aceh-Medan yaitu jalan dengan angka kecelakaan tinggi.

Kecepatan rata-rata di Jalan Banda Aceh-Medan pada hari Senin, Rabu, dan Sabtu adalah 48,73 km/jam, 49,34 $\mathrm{km} / \mathrm{jam}$, dan 48,53 km/jam, sedangkan Jalan Banda Aceh-Meulaboh pada hari Senin, Rabu, dan Sabtu adalah 43,23 km/jam, 43,72 km/jam, dan 44,36 km/jam. Dari hasil penelitian, Pengendara sepeda motor pada jalan dengan angka kecelakaan tinggi melaju dengan kecepatan yang relatif lebih tinggi dibandingkan pengendara pada jalan dengan angka kecelakaan rendah.

Setelah melakukan survey pelanggaran pada Jalan Banda Aceh-Medan dan Jalan Banda Aceh-Meulaboh terlihat bahwa Semua nilai chi-square hitung perbandingan kedua jalan ini lebih besar dari nilai chisquare tabel, maka kesimpulan dari penelitian ini adalah penerimaan hipotesis alternatif $\left(\mathrm{H}_{\mathrm{a}}\right)$ yaitu adanya perbedaan pelanggaran berupa kelengkapan dan perilaku pengendara sepeda motor pada Jalan Banda Aceh-Medan sebagai jalan dengan angka kecelakaan tinggi dan Jalan Banda Aceh-Meulaboh sebagai jalan dengan angka kecelakaan rendah.

Dari grafik dan tabel hasil pelanggaran di kedua jalan diketahui bahwa angka pelanggaran pengendara sepeda motor pada Jalan Banda Aceh-Medan relatif lebih tinggi dibandingkan angka pelanggaran pengendara sepeda motor pada Jalan Banda Aceh-Meulaboh. Pelanggaran pada kedua jalan ini didominasi oleh pengendara laki-laki yaitu sebanyak $78,9 \%$ pada Jalan Banda Aceh-Medan dan sebanyak $73,4 \%$ pada Jalan Banda Aceh-Meulaboh.

Dari penelitian ini diketahui bahwa pengendara sepeda motor pada Jalan Banda Aceh-Medan cenderung mengendarai sepeda motor dengan kecepatan yang relatif lebih tinggi karena volume lalu lintas yang relatif rendah, selain itu jumlah pelanggaran pengendara sepeda motor pada jalan ini relatif lebih tinggi dibandingkan dengan Jalan Banda Aceh-meulaboh. Kecepatan rata-rata dan jumlah pelanggaran yang relatif lebih tinggi pada jalan Banda Aceh-Medan dapat menjadi salah satu penyebab besarnya angka kecelakaan yang terjadi, sehingga jalan ini merupakan salah satu jalan yang rawan terjadinya kecelakaan lalu lintas.

\section{Kesimpulan dan Saran}

\subsection{Kesimpulan}

Jalan Banda Aceh-Medan sebagai jalan dengan angka kecelakaan tinggi memiliki volume lalu lintas yang relatif lebih rendah, kecepatan rata-rata relatif lebih tinggi, dan jumlah pelanggaran pengendara sepeda motor yang relatif lebih tinggi, sedangkan Jalan Banda Acehmeulaboh sebagai jalan dengan angka kecelakaan rendah memiliki volume lalu lintas yang relatif lebih tinggi, kecepatan rata-rata relatif lebih rendah dan jumlah pelanggaran pengendara sepeda motor yang relatif lebih rendah.

Setelah melakukan pengujian perbandingkan pelanggaran pengendara sepeda motor pada kedua jalan dengan menggunakan uji chi-square, didapat seluruh nilai chi-square hitung > nilai chi-square tabel, sehingga terjadi penolakan hipotesis nol $\left(\mathrm{H}_{0}\right)$ atau penerimaan hipotesis alternatif $\left(\mathrm{H}_{\mathrm{a}}\right)$ yaitu terdapat perbedaan pelanggaran berupa kelengkapan pengendara sepeda motor dan perilaku pengendara sepeda motor yang signifikan pada Jalan Banda Aceh-medan sebagai jalan dengan angka kecelakaan tinggi dan Jalan Banda AcehMeulaboh sebagai jalan dengan angka kecelakaan rendah.

\subsection{Saran}

Diharapkan penelitian ini dapat memberikan referensi untuk penelitian selanjutnya agar dapat lebih dikembangkan lagi, seperti dengan menambah lebih banyak ruas jalan yang akan dibandingkan, menambah lebih banyak titik pengamatan pada satu ruas jalan, serta menambah lebih banyak variabel pelanggaran yang ditinjau. Penelitian ini membandingkan jalan dengan klasifikasi jalan yang sama, diharapkan penelitian ini bisa dijadikan referensi untuk penelitian selanjutnya agar dapat membandingkan jalan dengan klasifikasi yang berbeda, bagaimana kaitan volume lalu lintas, kecepatan kendaraan serta pelanggaran lalu lintas pada kedua jalan tersebut.

\section{Daftar Pustaka}

[1] Pemerintah Indonesia, Undang-Undang Republik Indonesia Nomor 22 Tahun 2009 Tentang Lalu Lintas dan Angkutan Jalan, 2009.

[2] Sainuddin, L, Tinjauan kriminologis Pelanggaran Lalu Lintas Secara Masifyang Dilakukan oleh Pengantar Jenazah di Kota Makassar, Fakultas Hukum Universitas Hasanuddin, Makassar, 2015.

[3]Sukirman, S, Dasar-Dasar Perencanaan Geometrik Jalan, Nova, Bandung, 1999.

[4] Santoso, S, SPSS Versi 10 Mengolah Data Statistik Secara Profesional, PT Elex Media Komputindo Kelompok Gramedia, Jakarta, 2001. 